\title{
Renal Function Assessment Among Diabetic Patients in Asella Referral and Teaching Hospital, Assela, South East Ethiopia
}

\author{
Shimels Teshome Ayalneh", Million Getachew Mesfun, Getachew Abebe, Henok Getachew \\ College of Health Sciences, Arsi University, Asella, Ethiopia \\ Email address: \\ shimelisteshome35@gmail.com (S. T. Ayalneh) \\ ${ }^{*}$ Corresponding author

\section{To cite this article:} \\ Shimels Teshome Ayalneh, Million Getachew Mesfun, Getachew Abebe, Henok Getachew. Renal Function Assessment Among Diabetic \\ Patients in Asella Referral and Teaching Hospital, Assela, South East Ethiopia. Science Journal of Clinical Medicine. \\ Vol. 8, No. 2, 2019, pp. 17-20. doi: 10.11648/j.sjcm.20190802.13
}

Received: May 27, 2019; Accepted: July 1, 2019; Published: July 22, 2019

\begin{abstract}
: 1.5 million people died due to diabetes and more than half millions of them died because of diabetic kidney diseases in 2015. In Ethiopia, the frequency of chronic complications of diabetes is high and an increased occurrence of nephropathy, peripheral neuropathy, hypertension, and retinopathy was observed with longer duration of diabetes. However, there is limited data on the assessment of renal function among Diabetic patients at country level in general as well as specifically in Asella Referral \& Teaching Hospital. Retrospective study method was used and Cockroft-Gault formula was used to calculate the estimated Glomerular Filtration Rate. The data were analyzed using SPSS version-20 software and the Pvalue was calculated to see the statistically significant association (p-value $<0.05$ ) among different parameters. Among the total of 189 study subjects, $123(65.1 \%)$ was found to have evidence of renal damage. Of all 123 patients having renal damage, $76(40.2 \%)$ was stage $2,4(2.1 \%)$ was stage 4 . Diabetic patients whose age is $>50$ were 0.276 times at risk of developing diabetic renal damage than those aged $\leq 50(\mathrm{AOR}=0.276,95 \% \mathrm{CI}(0.133-0.574) \mathrm{p}=0.001)$
\end{abstract}

Keywords: Diabetes, Estimated GFR, Kidney Damage, Hypertension, Assela

\section{Introduction}

From 57 million global deaths in 2015, about 40 million were due to non-communicable diseases (NCDs) and diabetes accounts for 1.6 million [1]. The epidemiology of diabetes is increasing from time to time; in 2014, 422 million adults had diabetes $(8.5 \%$ of the world's population), almost doubling the global prevalence of diabetes since $1980[1,2]$.

In Sub-Saharan Africa (sSA), prevalence and burden of diabetes are rising quickly. The rate of undiagnosed diabetes is also high in most countries of $\mathrm{SSA}$, and individuals who are unaware they have the disease are at very high risk of chronic complications especially Endstage renal failure [3].

Diabetes is the leading cause of ESRD in both developed and emerging nations. According to WHO, 2015 report out of 1.6 million people died by diabetes and more than half a million peoples died because of kidney disease caused by diabetic complication [4]. In Ethiopia the frequency of chronic complications of diabetes is high. There is an increased occurrence of nephropathy, peripheral neuropathy, hypertension and retinopathy longer duration of diabetes [5].

Chronic diseases such as diabetes are major public health problems in Ethiopia and kidney disease is one of the commonest complaints in any Ethiopian hospital diabetic outpatient department. The overall prevalence of kidney disease in diabetic patients in Ethiopia range from 23.8\% [6] to $45.7 \%$ [5]. As the number of diabetic associated kidney disease complaints is increasing there is a need to systematically assess the trend of the disease and plan better strategies to at least minimize the incidence rate of the disease among the community.

However, the burden of renal damage among diabetic patients from this study area was not known. Therefore, the aim of this study was to assess the burden of diabetic 
associated kidney disease in the last two years among diabetic patients in Asella teaching and referral hospital.

\section{Methods and Materials}

\subsection{Study Area and Design}

This study was conducted in Arsi University, Assela Referral and Teaching Hospital which is found in Assela town, Arsi zone, Oromia Region, South East Ethiopia. It is located $175 \mathrm{~km}$ far from Addis Ababa Ethiopia. A Retrospective crossectional study design was conducted among know diabetic patients who were on follow up at Asella Referral and Teaching Hospital.

\subsection{Study Population and Sample Size}

Data of all diabetic patients, that have fully documented information on their respective logbooks, and who visited Asella Referral and Teaching Hospital at the time of follow up care from September 2016 to December 2018.

\subsection{Data Collection and Statistical Analysis}

All required data were collected from Laboratory test result registration logbook and DM out Patient Department (OPD) registration logbook. The raw data was entered and analyzed by SPSS version 20. Percentage and frequency were used to show the distribution of descriptive data using tables. Bi-variant and multi-variant analysis were employed using a logistic regression model for further analysis and interpreted based on the odds ratio and level of statistical significance at $\mathrm{p}$-value $<0.05$.

\subsection{Ethical Considerations}

Ethical clearance was obtained from the Arsi University ethical review committee and data was used for only this study.

\section{Result}

\subsection{Demographic Characteristics of the Study Subjects}

A total of 189 diabetic patients were enrolled in this study and screened for KD using eGFR (C-G method). Among the total 189 study subjects, $124(65.6 \%)$ was males and 65 $(34.4 \%)$ was females. The mean age of the study subjects was 49 years $( \pm 15.3)$ with the range between 19 to 80 years. Majority of the study subjects $29.1 \%$ were in the age group of 50-59 years and $0.5 \%$ were aged less than 20 years (Table 1 ).

Table 1. Demographic data (age and sex) distribution of 189 study subjects who were enrolled from Laboratory analysis result and DM OPD registration logbooks from September 2016 to December 2018 in Assela Referral and Teaching Hospital, Assela.

\begin{tabular}{llll}
\hline Demographic status & Frequency (Number) & Percentage (\%) \\
\hline \multirow{4}{*}{ Age group } & $<20$ & 1 & 0.5 \\
& $20-29$ & 28 & 14.8 \\
& $30-39$ & 22 & 11.6 \\
& $40-49$ & 31 & 16.4 \\
& $50-59$ & 55 & 29.1 \\
\multirow{4}{*}{ Sex } & $60-69$ & 37 & 19.6 \\
& $>=70$ & 15 & 7.9 \\
& male & 124 & 65.6 \\
\hline
\end{tabular}

\subsection{Prevalence of KIDNEY Damage}

Among all 189 study subjects, 123 (65.1\%) were found to have renal damage with the highest prevalence seen in men $(65.3 \%)$ but not significant $(\mathrm{P}>0.05)$. However, only $55.6 \%$ of patients had significant diabetic kidney damage. The study showed that there is a statically significance correlation between Hypertension and kidney damage $(p=0.05)$ and the age group of 60-69 years and significant kidney damage $(\mathrm{p}=$ 0.038) (Table 2).

Table 2. Prevalence of kidney damage among 189 study subjects who were enrolled from Laboratory analysis result and DM OPD registration logbooks from September 2016 to December 2018 in Assela Referral and Teaching Hospital, Assela.

\begin{tabular}{|c|c|c|c|c|}
\hline & & \multicolumn{2}{|c|}{ Renal damage } & \multirow{2}{*}{ Total } \\
\hline & & Normal & renal damage & \\
\hline \multirow{7}{*}{ Age group } & $<20, \mathrm{n}(\%)$ & $1(100.0 \%)$ & $0(0.0 \%)$ & $1(100.0 \%)$ \\
\hline & $20-29, \mathrm{n}(\%)$ & $11(39.3 \%)$ & $17(60.7 \%)$ & $28(100.0 \%)$ \\
\hline & $30-39, n(\%)$ & $10(45.5 \%)$ & $12(54.5 \%)$ & $22(100.0 \%)$ \\
\hline & $40-49, \mathrm{n}(\%)$ & $22(71.0 \%)$ & $9(29.0 \%)$ & $31(100.0 \%)$ \\
\hline & $50-59, \mathrm{n}(\%)$ & $11(20.0 \%)$ & $44(80.0 \%)$ & $55(100.0 \%)$ \\
\hline & $60-69, \mathrm{n}(\%)$ & $6(16.2 \%)$ & $31(83.8 \%)$ & $37(100.0 \%)$ \\
\hline & $>=70, \mathrm{n}(\%)$ & $5(33.3 \%)$ & $10(66.7 \%)$ & $15(100.0 \%)$ \\
\hline \multirow{2}{*}{ Sex } & Male, n(\%) & $43(34.7 \%)$ & $81(65.3 \%)$ & $124(100.0 \%)$ \\
\hline & Female, n(\%) & $23(35.4 \%)$ & $42(64.6 \%)$ & $65(100.0 \%)$ \\
\hline \multirow{2}{*}{ Hypertension status } & Hypertensive, n (\%) & $3(10.7 \%)$ & $25(89.3 \%)$ & $28(100.0 \%)$ \\
\hline & Non-hypertensive, n (\%) & $63(39.1 \%)$ & $98(60.9 \%)$ & $161(100.0 \%)$ \\
\hline
\end{tabular}

\subsection{KDIGO Staging of KD by eGFR and Albuminuria Categories}

Out of 123 study subjects with renal damage, $76(40.2 \%)$ are in stage 2 and $4(2.1 \%)$ was in stage 4 renal damage. No 
patients developed renal failure (Stage 5 KD) (Table 3)

Table 3. Staging of kidney damage among 189 study subjects who were enrolled from Laboratory analysis result and DM OPD registration logbooks from September 2016 to December 2018 in Assela Referral and Teaching Hospital, Assela.

\begin{tabular}{llll}
\hline Stages KD & Description & GFR (ml/min) \\
\hline Normal & Normal GFR & Noml $/ \mathrm{min}$ or above without albuminuria & $35(18.5 \%)$ \\
Stage 1 & Kidney damage (e.g., protein in the urine) with normal GFR & $90 \mathrm{ml} / \mathrm{min}$ or above with albuminuria & $31(16.4 \%)$ \\
Stage 2 & Kidney damage with a mild decrease in GFR & $60 \mathrm{ml} / \mathrm{min}$ to $89 \mathrm{ml} / \mathrm{min}$ & $76(40.2 \%)$ \\
Stage 3 & Moderate decrease in GFR & $30 \mathrm{ml} / \mathrm{min}$ to $59 \mathrm{ml} / \mathrm{min}$ & $43(22.8 \%)$ \\
Stage 4 & Severe reduction in GFR & $15 \mathrm{ml} / \mathrm{min}$ to $29 \mathrm{ml} / \mathrm{min}$ \\
Stage 5 & Kidney failure & Less than $15 \mathrm{ml} / \mathrm{min}$ & $4(2.1 \%)$ \\
\hline
\end{tabular}

\subsection{Risk Assessment of Renal Damage}

Diabetic patients whose age is $>50$ were 0.276 times at risk of developing diabetic renal damage than those aged $\leq 50$ $(\mathrm{AOR}=0.276,95 \% \mathrm{CI}(0.133-0.574) \mathrm{p}=0.001)$. (Table 4)

Table 4. Comparison of Risk factor prevalence between DKD and non-DKD among 81 study subjects who were enrolled from Laboratory analysis result and DM OPD registration logbooks from September 2016 to December 2018 in Assela Referral and Teaching Hospital, Assela.

\begin{tabular}{llll}
\hline & No-DKD & DKD & P-value \\
\hline $\begin{array}{l}\text { Age Category, n (\%) } \\
<=50\end{array}$ & $51(49.5)$ & $52(50.5)$ & 0.001 \\
$>50$ & $15(17.4)$ & $71(82.6)$ & \\
$\begin{array}{l}\text { Sex, n (\%) } \\
\text { Male }\end{array}$ & & \\
$\begin{array}{l}\text { Female } \\
\text { Glucose level, n (\%) }\end{array}$ & $43(34.7)$ & $81(65.3)$ & 0.670 \\
$\begin{array}{l}\text { Normal } \\
\text { High }\end{array}$ & $23(35.4)$ & $42(64.6)$ & \\
$\begin{array}{l}\text { Hypertension, n (\%) } \\
\text { Haypertensive }\end{array}$ & $11(23.9)$ & $35(76.1)$ & 0.646 \\
Non-Hypertensive & $55(38.5)$ & $88(61.5)$ & \\
\hline
\end{tabular}

\section{Discussion}

This study evaluated 189 diabetic subjects overall. The population studied was predominantly men who cover $65.6 \%$ of the participants with a female to male ratio of $1: 1.9$ which agrees with the Global estimates that suggest in sSA there is an excess of males with diabetes [8]. Similar gender disparity has been observed in a study conducted in Butajira, which found $57.5 \%$ of study subjects were male [6]. This disparity may represent the health-seeking behavior of the patients attending DM-OPD, although the reasons for the skewed gender proportions of KD are not known.

The mean age of the study participants was 49 years $( \pm$ 15.3). Majority of the patients $(82.6 \%)$ with $\mathrm{KD}$ were older than 50 years. A similar study conducted in Jamaica found the mean age of their study population was $55.4 \pm 12.9$ years [9]. A cross-sectional survey conducted in diabetic outpatients in the USA found the mean age of participants $61.7 \pm 11.2$ years [10]. Aging is a known risk factor for the decline in renal function. This difference in age between Ethiopians and western countries can be due to population characteristics, socioeconomic status, healthcare organization, and differences in health-seeking patterns.
Our prevalence estimate of KD was lower than $86.3 \%$ reported in Jamaica [9] and $82.6 \%$ in Kenya [11], but higher than that of $25.3 \%$ reported in Brazil [12] and 27.9\% in Spain [13]. These differences in KD prevalence might be because of the differences in case difference in creatinine assays and calibration or due to the use of Cockroft-Gault equation for estimation of GFR could also have led to an underestimation of GFR \& thus a higher prevalence of KD.

A cross-sectional study done in Japanese patients with diabetes found a $46 \%$ prevalence of KD [14], but they used a different formula recommended by the Japanese nephrology society to estimate GFR. A cross-sectional study conducted in the USA shows that the prevalence of $\mathrm{KD}$ in patients with diabetes was found to be $39.7 \%$ [15]. The lower prevalence of $\mathrm{KD}$ in these non-African populations is not unusual as there have been studies which have shown an increased risk of diabetic renal disease in African than in Caucasian populations [16]. All the subjects included in this study were not known whether they are symptomatic or asymptomatic for $\mathrm{KD}$ but this result may indicate our clinicians in the diabetes outpatient clinics should have to be aware of the high prevalence of KD and referral made to nephrologists as early as possible.

As for risk factors, this study found a significant association between older age group ( $>50$ years), and KD. This is consistent with findings from other studies $[6,9,11$, 12]. It was reported that eGFR will decline gradually with age and at the age $>50$ years whatever the equations were used; $25 \%$ of the diabetics will have eGFR $<90 \mathrm{~mL} / \mathrm{min}$ [17]. Thus, to screen diabetics in this age group is an important strategy for the detection of CKD and to improve the quality of patients with diabetes.

\section{Conclusion and Recommendation}

The study identified a high prevalence of $\mathrm{KD}$ which is $65.1 \%$ among diabetic adult patients attending in Asella Referral and Teaching Hospital, Southeast Ethiopia. However, there are no diabetic patients who developed kidney failure. Despite this, the study determined older age as an independent risk factor $(\mathrm{P}<0.005)$ for the development of kidney damage. Therefore, despite the regulation of blood glucose as a part of follow up management of DM, regulation and assessment of renal function will decrease the occurrence of renal damage due to diabetes. 


\section{Limitation of the Study}

This is a retrospective data analysis and doesn't allow for review of long-term outcomes. Moreover, Lack of data related to the type of diabetes, the duration of diabetes, the duration when the antidiabetic treatment began, and types of treatment given since onset; forced not to show their effects on the development of significant renal damage.

\section{Acknowledgements}

I would like to thank all the laboratory staff at the Asella teaching and Referral Hospital for their invaluable support during data collection.

\section{References}

[1] WHO, Global Health Estimates: Estimated deaths by cause, age and sex 2000-2015. 2016.

[2] WHO, global NCD target halt the rise in diabetes. 2016.

[3] Mbanya, J. C. N., et al., Diabetes in sub-Saharan Africa. The Lancet, 2010. 375(9733): p. 2254-2266.

[4] WHO, Global report on diabetes. 2015.

[5] Worku, D., L. Hamza, and K. Woldemichael, Patterns of diabetic complications at Jimma University specialized hospital, southwest Ethiopia. Ethiopian journal of health sciences, 2010. 20(1).

[6] Fiseha, T., M. Kassim, and T. Yemane, Prevalence of chronic kidney disease and associated risk factors among diabetic patients in southern Ethiopia. American Journal of Health Research, 2014. 2(4): p. 216-221.

[7] Green, A., N. Christian Hirsch, and S. Krøger Pramming, The changing world demography of type 2 diabetes. Diabetes/metabolism research and reviews, 2003. 19(1): p. 37.
[8] King, H., R. E. Aubert, and W. H. Herman, Global burden of diabetes, 1995-2025: prevalence, numerical estimates, and projections. DiabetesCare, 1998. 21(9): p. 1414-1431.

[9] Ferguson, T. S., et al., Prevalence of chronic kidney disease among patients attending a specialist diabetes clinic in Jamaica. The West Indian medical journal, 2015. 64(3): p. 201.

[10] Charuhas V. Thakar, A. C., Jonathan Himmelfarb, and Anthony C. Leonard, Acute Kidney Injury Episodes and Chronic Kidney Disease Risk in Diabetes Mellitus. Clinical Journal of the American Society of Nephrology, 2011. 6: p. 2567-2572.

[11] Nyamai, The Burden of Chronic Kidney Disease in Ambulant Type 2 Diabetes Patients at Kenyatta National Hospital Diabetes Outpatient Clinics. 2014.

[12] Fontela, P. C., et al., Estimated glomerular filtration rate in patients with type 2 diabetes mellitus. Revista da Associação Médica Brasileira, 2014. 60(6): p. 531-537.

[13] Antonio Rodriguez-Poncelas, J. G.-O., Josep Franch-Nadal, and RedGDPS Study Group, Prevalence of chronic kidney disease in patients with type 2 diabetes in Spain: PERCEDIME2 study. BioMed central 2013.

[14] Ohta, M., et al., Comparison of the prevalence of chronic kidney disease in Japanese patients with Type 1 and Type 2 diabetes. Diabetic Medicine, 2010. 27(9): p. 1017-1023.

[15] Koro, C. E., B. H. Lee, and S. J. Bowlin, Antidiabetic medication use and prevalence of chronic kidney disease among patients with type 2 diabetes mellitus in the United States. Clinical Therapeutics, 2009. 31(11): p. 2608-2617.

[16] Young, B. A., C. Maynard, and E. J. Boyko, Racial differences in diabetic nephropathy, cardiovascular disease, and mortality in a national population of veterans. Diabetes Care, 2003. 26(8): p. 2392-2399.

[17] Foundation, N. K., frequently asked questions about GFR estimates. 2014. 